\title{
Mood effects of 24-hour tryptophan depletion in healthy first-degree relatives of patients with affective disorders.
}

Citation for published version (APA):

Klaassen, T., Riedel, W. J., van Someren, A., Deutz, N. E. P., Honig, A., \& van Praag, H. M. (1999). Mood effects of 24-hour tryptophan depletion in healthy first-degree relatives of patients with affective disorders. Biological Psychiatry, 46(4), 489-497. https://doi.org/10.1016/S0006-3223(99)00082-7

Document status and date:

Published: 01/01/1999

DOI:

10.1016/S0006-3223(99)00082-7

Document Version:

Publisher's PDF, also known as Version of record

Document license:

Taverne

Please check the document version of this publication:

- A submitted manuscript is the version of the article upon submission and before peer-review. There can be important differences between the submitted version and the official published version of record.

People interested in the research are advised to contact the author for the final version of the publication, or visit the DOI to the publisher's website.

- The final author version and the galley proof are versions of the publication after peer review.

- The final published version features the final layout of the paper including the volume, issue and page numbers.

Link to publication

\footnotetext{
General rights rights.

- You may freely distribute the URL identifying the publication in the public portal. please follow below link for the End User Agreement:

www.umlib.nl/taverne-license

Take down policy

If you believe that this document breaches copyright please contact us at:

repository@maastrichtuniversity.nl

providing details and we will investigate your claim.
}

Copyright and moral rights for the publications made accessible in the public portal are retained by the authors and/or other copyright owners and it is a condition of accessing publications that users recognise and abide by the legal requirements associated with these

- Users may download and print one copy of any publication from the public portal for the purpose of private study or research.

- You may not further distribute the material or use it for any profit-making activity or commercial gain

If the publication is distributed under the terms of Article $25 \mathrm{fa}$ of the Dutch Copyright Act, indicated by the "Taverne" license above, 


\title{
Mood Effects of 24-Hour Tryptophan Depletion in Healthy First-Degree Relatives of Patients with Affective Disorders
}

\author{
Tineke Klaassen, Wim J. Riedel, Astrid van Someren, Nicolaas E.P. Deutz, \\ Adriaan Honig, and Herman M. van Praag
}

Background: Acute tryptophan (TRP) depletion was evaluated in healthy volunteers with or without a family history of major affective disorder ( $F H+$ versus $\mathrm{FH}-$ ).

Methods: Twenty-seven subjects (16 FH+, $11 \mathrm{FH}-$ ) received $100 \mathrm{~g}$ of an amino acid mixture with and without TRP according to a placebo-controlled, double-blind cross-over design and a diet devoid of TRP for the next 24 hours.

Results: The ratio TRP/large neutral amino acids declined to $22 \%$ of baseline values after 6 hours, and increased during the night reaching $85 \%$ of baseline after 24 hours. Overall, after 6 hours, TRP depletion lead to a lowering of mood, but after 24 hours, these changes were no longer detected. Mood changes and gastrointestinal side effects were significantly more evident in $\mathrm{FH}+$ subjects than in $\mathrm{FH}-$ subjects.

Conclusions: Our data support the hypothesis that subjects with a positive family history for depression are predisposed to increased vulnerability to the adverse consequences of serotonergic imbalance. Biol Psychiatry 1999;46:489-497 (C) 1999 Society of Biological Psychiatry

Key Words: Tryptophan depletion, mood, affective disorder, family history, healthy subjects

\section{Introduction}

A cute tryptophan (TRP) depletion as a biochemical model for depressed mood has become increasingly popular since it was first described (Moja et al 1984). In rats, TRP depletion leads to a diminished turnover of serotonin (Schaechter and Wurtman 1989; Young et al 1989). In humans, ingestion of 50 to $100 \mathrm{~g}$ of a balanced

From the Brain and Behaviour Institute, Department of Psychiatry and Neuropsychology (TK, WJR, AvS, AH, HMvP); and the Department of General Surgery (NEPD), Maastricht University, Maastricht, The Netherlands.

Address reprint requests to Wim J. Riedel, Department of Psychiatry and Neuropsychology, University of Maastricht, P.O. Box 616, NL-6200 MD MAASTRICHT, The Netherlands.

Received October 28, 1998; revised February 26, 1999; accepted March 29, 1999. amino acid mixture without TRP leads to a $75 \%$ to $90 \%$ reduction in plasma TRP concentrations within 4 to 6 hours (Young et al 1985). Recently, it has also been shown that in human subjects, TRP depletion leads to a decreased rate of 5-HT synthesis in the brain (Nishizawa et al 1997) and to a lowering of CSF 5-HIAA 8 to 12 hours after the amino acid drink (Carpenter 1998). These data suggest that TRP depletion results in substantial reduction of central 5-HT turnover.

TRP depletion affects many psychological and physiologic functions such as cognition, nocturnal melatonin secretion, sleep, breathing patterns, memory and learning, anxiety, aggression, and food selection (Benkelfat et al 1994; Cleare and Bond 1995; Kent et al 1996; Menkes et al 1994; Moeller et al 1996; Park et al 1994; Smith et al 1987; Weltzin et al 1994, 1995; Young et al 1988, 1985; Zimmermann et al 1993). However, several studies have shown that TRP depletion usually does not lead to a lowering of mood in healthy subjects. One study with healthy male subjects who had elevated scores on a depression scale, showed a slight, but not clinically significant, mood-lowering effect of tryptophan depletion (Young et al 1985). Two studies with healthy subjects showed that healthy female subjects were sensitive to the mood-lowering effect of tryptophan depletion, whereas healthy male subjects were not (Ellenbogen et al 1996; Smith et al 1997a). Healthy subjects with a positive family history of depression show significantly more depressed mood after TRP depletion than healthy subjects without such a family history (Benkelfat et al 1994). Acute TRP depletion in depressed patients in remission who had been treated with serotonergic antidepressants caused clinically significant depressive symptoms within 6 hours (Delgado et al 1989, 1991; Lam et al 1996; Smith et al 1997b). These symptoms disappeared within 24 hours after discontinuation of the TRP depletion.

A possible explanation for these findings might be that it is more difficult to disrupt brain neurotransmitter systems in healthy subjects than in subjects who have been depressed or in subjects with a positive family history $(\mathrm{FH})$ for depression. 
This alleged biological factor (trait-marker) could render some groups of subjects more sensitive to TRP depletion. Alternatively, symptoms could be elicited in any group of subjects provided the depletion lasts long enough. Hence, TRP depletion for 5 to 7 hours may be too short to elicit symptoms in healthy subjects. In rats, it has been possible to achieve a sharp and longlasting (24 hour) decline in plasma and brain tryptophan and in brain 5HT (Biggio et al 1974). Delgado and colleagues (1990) found a significant lowering of mood after 24 hours in remitted depressed patients using an amino acid mixture devoid of tryptophan.

For that reason, we developed a method to deplete subjects of TRP for 12 to 24 hours, using an amino acid mixture and a diet devoid of TRP. Our first hypothesis was that prolonged TRP depletion would lead to more symptoms of depression in healthy subjects after 24 hours than after 6 hours. Furthermore, we were interested in the influence of the family history on symptoms of depression after TRP depletion. Benkelfat and co-workers (1994), showing that a positive family history of depression was associated with increased sensitivity to TRP depletion, used a rather strict definition of positive family history of depression $(\mathrm{FH}+)$ in that subjects had to have three or more registered family members with recurrent depression of whom at least one should be a first-degree relative (Benkelfat et al 1994). The lifetime risk for major affective disorder (MAD) is estimated to be $7 \%$ to $25 \%$ in the general population (Charney and Weissman 1988). Family studies, however, have shown that the presence of one depressed first-degree relative already leads to a two- to three-fold increased relative risk for major depression (Charney and Weissman 1988). For this reason, we defined $\mathrm{FH}+$ as having at least one first-degree relative with depression and hypothesized that $\mathrm{FH}+$ subjects would experience greater mood changes as a result of TRP depletion than subjects without a first-degree relative with depression.

One of the aims of this study was to maintain a depleted state for 24 hours. Ideally, one should have assessed the TRP blood levels frequently during the 24 hours in all subjects. However, this would impose too great a burden on the subjects. For that reason, we decided to conduct in addition to the main behavioral study, a separate small pharmacokinetic study to monitor TRP levels regularly during 24 hours following TRP depletion.

We report the results and methods of the main study and the pharmacokinetic study subsequently.

\section{Main Behavioral Study}

\section{Methods and Materials}

\section{Subjects}

Thirty-four healthy volunteers were recruited, of whom 15 women and 12 men completed the experiment [mean age: $30.9 \pm$
10.9 (SD); range 18 to 61; mean body mass index (weight/ length ${ }^{2}$ ): $23.5 \mathrm{~kg} / \mathrm{m}^{2}$ ]. The subjects were free of medication, except for oral contraceptives. A complete medical examination was carried out. Exclusion criteria were cardiac, hepatic, renal, pulmonary, neurologic, gastrointestinal, hematologic, or psychiatric conditions, as determined from the history, physical examination, ECG, and routine blood chemistry analyses. Further exclusion criteria were a history of alcohol or drug abuse, excessive drinking, dieting, and susceptibility to premenstrual syndrome as determined by questioning the subject. The latter susceptibility was assessed with the question "Do you regularly experience significant mood swings during your menstrual cycle, especially in the week before the onset of the periods?" A structured psychiatric interview, the MINI (Sheehan et al 1994), was carried out to exclude psychiatric disorders. A validated Dutch version of the subjective complaint list, SCL-90 (Arrindell and Ettema 1986), was used to verify the absence of other psychopathology. The Research Diagnostic Criteria (RDC) (Spitzer et al 1975) were used to ascertain that subjects had no prior episode of MAD or manic depressive illness. Inclusion criterion for subjects at risk for MAD was the presence of at least one first-degree relative (siblings or parents) with at least one episode of depression (including bipolar disorder type II). For subjects without genetic risk for MAD, the absence of MAD in all first- and second-degree relatives was the inclusion criterion. Family History Research Diagnostic Criteria were used to verify these criteria (Endicott et al 1975).

All subjects were interviewed about their family history before the start of the study. Parents or nearest other first-degree relatives were telephoned for additional information. Depressed relatives had to be registered at our clinic and had to have experienced at least one episode of major depression or bipolar disorder type II, and had to meet Research Diagnostic Criteria for major depression or bipolar disorder type I or II. Second- or third degree-relatives had to meet Family History Research Diagnostic Criteria (Endicott et al 1975) for these disorders in order to be considered affected.

Two groups were formed, one consisting of first-degree relatives with depression [positive family history $(\mathrm{FH}+) 7 \mathrm{men}$, 9 women, $29 \pm 11$ years] and one group without first-degree relatives with depression [negative family history $(\mathrm{FH}-), 6$ women, 5 men, $33 \pm 11$ years]. All subjects came from different families. Eight female subjects took oral contraceptives.

Table 1 shows the demographic and family history characteristics of the two groups. There were no statistically significant differences with regard to demographic and family characteristics between the groups.

The study was approved by the Medical Ethics Review Committee of the University Hospital Maastricht, The Netherlands. All subjects signed voluntary informed consent prior to the study and were paid for their participation.

\section{Procedures}

Subjects arrived at the laboratory at 8:30 AM after an overnight fast. Mood assessment was completed at 9:00 AM (= baseline or $\mathrm{t}_{0} ; \mathrm{t}_{\mathrm{x}}$ denotes time elapsed since treatment administration, $\mathrm{x}$ referring to the number of hours after $t_{0}$ ). The day of the 
Table 1. Demographic Characteristics of the FH+ and FHGroups (Mean \pm SD)

\begin{tabular}{lcc}
\hline & $\begin{array}{c}\text { Family history } \\
\text { positive } \\
(\mathrm{FH}+)\end{array}$ & $\begin{array}{c}\text { Family history } \\
\text { negative } \\
(\mathrm{FH}-)\end{array}$ \\
\hline Women & $n=9$ & $n=6$ \\
Men & $n=7$ & $n=5$ \\
Age & $29 \pm 11$ years & $33 \pm 10$ years \\
Body mass index & $22 \pm 2 \mathrm{~kg} / \mathrm{m}^{2}$ & $25 \pm 5 \mathrm{~kg} / \mathrm{m}^{2}$ \\
SCL-90 score & $110 \pm 24$ & $97 \pm 6$ \\
Depressed family members & & \\
1st degree & 19 & 0 \\
2nd degree & 8 & 2 \\
3rd degree & 1 & 4 \\
\hline
\end{tabular}

${ }^{a}$ Includes both subjects with unipolar and bipolar depression. The numbers represent the total number of subjects in the whole group that met Family History Research Diagnostic Criteria.

menstrual cycle was recorded in female subjects. Thereafter, subjects ingested the amino acid mixture as quickly as possible, but within 2 hours. The subjects remained in the laboratory until after the subjective mood assessments at $\mathrm{t}_{6}$, except for a 30-min guided standardized walk through the hospital with the test assistant, and were allowed to read, study, or watch an emotionally neutral video. The study was conducted according to a double-blind, placebo-controlled, balanced cross-over design. All subjects participated in a TRP depletion (TRP-) session and in a placebo (PLA) session, which were separated by at least 4 days. In each of the two sessions, subjects had to ingest $100 \mathrm{~g}$ of an amino acid mixture with or without TRP, followed by a diet containing $19 \mathrm{mg}$ TRP, which had to be adhered to for the next 24 hours. This diet was identical in both sessions and consisted of six slices of bread with a total of $1.1 \mathrm{~g}$ protein, butter, jam, two apples, $200 \mathrm{~g}$ applesauce, tea, lemonade, and mints ad libitum. At $\mathrm{t}_{7}, \mathrm{t}_{11}$, and $\mathrm{t}_{14}$, an additional $10 \mathrm{~g}$ of that days' amino acid mixture was ingested in order to keep TRP levels low. These timepoints were arbitrarily chosen.

After these assessments, subjects went home with their food supply and dietary instructions. A detailed description of all food and beverages consumed (time and amount) was kept by each subject, in order to encourage strict diet adherence. The next morning, the subjects returned for the last assessments at $t_{24}$. Afterwards, they received a protein-rich meal to compensate for possible deficiencies.

\section{Amino Acid Mixtures}

The TRP-deficient amino acid mixture was made according to Young and colleagues (1985) and contained 15 free amino acids in a total amount of $100 \mathrm{~g}$. The placebo mixture contained the same amino acids plus $3 \mathrm{~g}$ of L-tryptophan. A mixture of $38 \mathrm{~g}$ fat and $62 \mathrm{~g}$ carbohydrate was added in order to dissolve the amino acids. Mixtures were flavored with artificial orange (first test day) or apricot flavor (second test day). The mixture contained $1000 \mathrm{kcal}$. Tap water $(300 \mathrm{~mL})$ was added to $100 \mathrm{~g}$ of the mixture on the morning of the experiment. The mixtures were identical in appearance.

We added $3 \mathrm{~g}$ of TRP to the amino acid mixture instead of
$2.3 \mathrm{~g}$, as used by Young and co-workers (1985), on the basis of the results of Weltzin and co-workers (1994). They added $2.3 \mathrm{~g}$ and $4.6 \mathrm{~g}$ of TRP to the amino acid mixture and assessed the ratio of TRP/ $\Sigma$ LNAA (sum of the large neutral amino acids: tyrosine, leucine, isoleucine, valine, and phenylalanine) at 3 and 7 hours after the administration of the mixture. The ratio provides an estimation of TRP uptake in the central nervous system (Fernstrom 1981).

The mixture containing $2.3 \mathrm{~g}$ of TRP led to a significant $45 \%$ decrease in brain uptake of TRP, while $4.6 \mathrm{~g}$ of TRP led to a maximum $154 \%$ increase at 3 hours. We chose an amount in between, assuming that this amount would not affect the TRP/ $\Sigma$ LNAA ratio and hence, brain TRP uptake, and would thus serve as an inactive placebo. Our findings showed that our placebo amino acid mixture with $3.0 \mathrm{~g}$ TRP led to a slight decrease $(11 \%)$ in the TRP/ $\Sigma$ LNAA ratio.

\section{Subjective Assessments}

At $t_{0}, t_{6}$ and $t_{24}$, subjects were administered the Profile of Mood States Scale (POMS) (McNair et al 1971). The POMS consists of five separate mood scales (depression, tension, vigor, anger, and fatigue), ranging from 0 to 24 , each based on six items ranging from 0 to 4 . Thus, each of these five mood dimensions yielded a score. Furthermore, an overall POMS score, reflecting "mood level," was constructed by summing the scores for the five subscales, after changing the polarity of the vigor subscale $(\mathrm{y}=$ $24-\mathrm{x})$.

A list (5-point scales) of 10 vegetative side effects was used to determine the severity of the side effect. The list contained the following items: headache, feeling cold, feeling hot, dizziness, transpiration, blurred vision, nausea, palpitations, dry mouth, and abdominal complaints. Scores for the 10 side effect items were summed, yielding one vegetative side effect severity measure at each assessment. Finally, some computerized cognitive tests were carried out, which are described elsewhere (Riedel et al 1999).

\section{Biochemical Analysis}

At $t_{0}, t_{6}$, and $t_{24}$, venous blood was taken and immediately placed on ice and centrifuged within $30 \mathrm{~min}$ for $5 \mathrm{~min}$ at $1000 \mathrm{~g}$ at $4^{\circ} \mathrm{C}$. An aliquot of $100 \mu \mathrm{L}$ of plasma was then mixed with $4 \mathrm{mg}$ sulphasalicyl-acid and frozen at $-80^{\circ} \mathrm{C}$ until analysis (van Eijk et al 1994). Total plasma concentrations of TRP and other amino acids were measured by high-performance liquid chromatography (van Eijk et al 1993). In addition to total plasma TRP concentrations, the ratio of TRP/ $\Sigma$ LNAAs was determined.

\section{Statistical Analysis}

Results were analyzed using SPSS 8.0 for Windows statistical packages. Primary outcome measures were the POMS scores. As distributions of the scores were skewed, nonparametric tests were used. Differences between TRP depletion and placebo were analyzed using Wilcoxon's signed rank tests at $t_{0}, t_{6}$ and $t_{24}$. TRP depletion-placebo difference scores at $t_{0}, t_{6}$ and $t_{24}$ were tested for the $\mathrm{FH}+/ \mathrm{FH}-$ groups, using Mann-Whitney $U$ tests. Results 
Table 2. Subjective Mood Assessments

\begin{tabular}{|c|c|c|c|c|c|c|c|}
\hline POMS Subscale & FH & $\mathrm{TRP}_{\mathrm{t}}$ & PLA $_{6}$ & TRP - PLA $_{6}$ & TRP $t_{24}$ & PLA t $t_{24}$ & TRP - PLA t $_{24}$ \\
\hline \multirow[t]{2}{*}{ Depression } & + & $2.13 \pm 3.22$ & $0.19 \pm 0.54$ & $1.94 \pm 3.17$ & $0.36 \pm 0.84$ & $0.20 \pm 0.56$ & $0.14 \pm 1.10$ \\
\hline & - & $0.18 \pm 0.40$ & $0.18 \pm 0.60$ & $0.00 \pm 0.45$ & $0.09 \pm 0.30$ & $0.10 \pm 0.32$ & $0.00 \pm 0.00$ \\
\hline \multirow[t]{2}{*}{ Tension } & + & $1.56 \pm 2.19$ & $1.31 \pm 3.50$ & $0.25 \pm 2.02$ & $0.86 \pm 1.29$ & $0.80 \pm 2.31$ & $0.00 \pm 1.71$ \\
\hline & - & $0.64 \pm 1.21$ & $0.18 \pm 0.40$ & $0.45 \pm 1.04$ & $0.09 \pm 0.30$ & $0.10 \pm 0.32$ & $0.00 \pm 0.00$ \\
\hline \multirow[t]{2}{*}{ Tiredness } & + & $4.38 \pm 5.84$ & $2.31 \pm 4.06$ & $2.06 \pm 4.39$ & $2.64 \pm 4.24$ & $1.27 \pm 3.06$ & $1.29 \pm 4.12$ \\
\hline & - & $1.27 \pm 1.49$ & $2.73 \pm 4.52$ & $-1.45 \pm 4.30$ & $0.27 \pm 0.47$ & $0.10 \pm 0.32$ & $0.20 \pm 0.42$ \\
\hline \multirow[t]{2}{*}{ Anger } & + & $1.06 \pm 1.73$ & $0.50 \pm 1.10$ & $0.56 \pm 1.46$ & $0.64 \pm 1.08$ & $0.20 \pm 0.56$ & $0.43 \pm 1.09$ \\
\hline & - & $0.09 \pm 0.30$ & $0.64 \pm 1.57$ & $-0.55 \pm 1.51$ & $0.36 \pm 1.21$ & $0.10 \pm 0.32$ & $0.30 \pm 0.95$ \\
\hline \multirow[t]{2}{*}{ Vigour } & + & $12.44 \pm 5.51$ & $14.31 \pm 2.91$ & $-1.88 \pm 4.46$ & $13.79 \pm 4.85$ & $15.07 \pm 3.56$ & $-1.29 \pm 3.10$ \\
\hline & - & $15.36 \pm 5.05$ & $14.82 \pm 4.67$ & $0.54 \pm 2.98$ & $16.27 \pm 3.77$ & $16.60 \pm 3.98$ & $-0.70 \pm 1.57$ \\
\hline
\end{tabular}

Means and standard deviations and the respective TRP-PLA difference scores assessed at $\mathrm{t}_{6}$ and $\mathrm{t}_{24}$ of separate subscales of POMS are broken down by FH. FH, family history; TRP, acute tryptophan depletion; PLA, placebo condition.

were considered significant if $p<.05$. Trend significant results will be described when $.05<p<.10$. Differences between TRP blood concentrations and TRP/ $\Sigma$ LNAA ratio in TRP depletion and placebo sessions at $t_{0}, t_{6}$ and $t_{24}$, were analyzed using two-way repeated measures MANOVA, using treatment condition as the within subjects factor (TRP depletion versus placebo) and $\mathrm{FH}$ as between subjects factor.

\section{Results}

\section{Adverse Events}

Thirty-four subjects entered the study. Seven subjects withdrew from the experiment after the first treatment session. Two subjects withdrew for reasons unrelated to the treatment. Five withdrew because of adverse effects related to the treatment: four felt nauseous, three of whom vomited, and one subject could not adhere to the tryptophan-poor diet. All were women, six $\mathrm{FH}-$ and one $\mathrm{FH}+$. They all dropped out during the first session. Three subjects dropped out after TRP-depletion and four subjects dropped out after ingestion of the placebo mixture.

\section{Missing Data}

Because of difficulties in taking blood, samples were not available for two subjects at $t_{6}$ and one subject at $t_{24}$ in the TRP-depletion condition and for two subjects in the placebo condition at $t_{24}$.

\section{Side Effects}

At $t_{6}$, the incidence of side effects was low, with most subjects rating side effects as 0 . The only side effect which distinguished TRP-depletion from placebo was the feeling of nausea. One subject in the placebo condition and seven subjects in the TRP-depletion condition reported nausea at $\mathrm{t}_{6}$. Five of them were in the $\mathrm{FH}+$ group and five were women. However, these subjects were not the same as those who responded to TRP-depletion by reporting more depressed feelings. Six female and two male subjects in the $\mathrm{FH}+$ group and one male subject in the $\mathrm{FH}-$ group reported more depressed feelings at $\mathrm{t}_{6}$ after TRP depletion relative to placebo. There were only two female subjects and one male subject in the FH+ group who reported both an increase in feelings of depression and nausea at $t_{6}$ after TRP depletion relative to placebo.

\section{Subjective Mood Assessments}

Overall, there were no significant differences in baseline $\left(\mathrm{t}_{0}\right)$ POMS scores between the placebo and the TRP depletion session. TRP depletion led to a significant lowering of mood as expressed by the summed POMS scores at $\mathrm{t}_{6}$ compared to placebo $(Z=-2.18$, df $=26$, $p=.029)$. This was due to an increase in the mean POMS depression score to 1.3 whereas after placebo, this score was .2 $(Z=-2.16$, df $=26, p=.03)$. No other POMS subscales and none of the secondary outcome measures were significantly different at $\mathrm{t}_{6}$. At $\mathrm{t}_{24}$, POMS scores did not differ between groups.

At $\mathrm{t}_{6}$, significantly more side effects were reported after TRP depletion $(Z=-2.90, \mathrm{df}=26, p=.004)$, and especially more reports of nausea $(Z=-2.27, \mathrm{df}=26$, $p=.023)$. No differences in side effects were found at $\mathrm{t}_{0}$ and $\mathrm{t}_{24}$.

TRP depletion affected subjects with and without firstdegree relatives with depression differently at $t_{6}$. The results are summarized in Table 2. The FH+ group responded to TRP depletion with a significant lowering of mood, as expressed by the summed POMS scores at $\mathrm{t}_{6}$, whereas the $\mathrm{FH}-$ group did not (Mann-Whitney $U, Z=$ -2.27 , df $=26, p=.029)$. FH+ subjects had significantly higher scores for the depression $(Z=$ $-2.06, \mathrm{df}=26, p=.04)$ and fatigue $(Z=-2.19$, $\mathrm{df}=26, p=.029)$ subscales than $\mathrm{FH}-$ subjects. $\mathrm{FH}+$ subjects also tended to feel more anger than $\mathrm{FH}-$ subjects $(Z=-1.65, \mathrm{df}=26, p<.1)$. There were no significant differences between the two groups at $t_{24}$.

$\mathrm{FH}+$ subjects experienced significantly more vegeta- 
Table 3. Means and Standard Errors of the Blood Plasma Levels of TRP and TYR and the TRP/ $\Sigma$ LNAA and TYR/ $\Sigma$ LNAA Ratio

\begin{tabular}{|c|c|c|c|c|}
\hline \multirow[b]{2}{*}{ Measure } & \multirow[b]{2}{*}{ Treatment } & \multicolumn{3}{|c|}{ Time after AA drink } \\
\hline & & $\begin{array}{c}\mathrm{t}_{0} \text { Mean } \\
(\mathrm{SE})\end{array}$ & $\begin{array}{c}\mathrm{t}_{6} \text { Mean } \\
(\mathrm{SE})\end{array}$ & $\begin{array}{c}\mathrm{t}_{24} \text { Mean } \\
\quad(\mathrm{SE})\end{array}$ \\
\hline \multirow[t]{2}{*}{ TRP (mmol/L) } & $\mathrm{T}+$ & $46.7(1.8)$ & $56.8(3.4)$ & $45.6(1.8)$ \\
\hline & $\mathrm{T}-$ & 47.0 (1.6) & $15.6(3.3)$ & $41.5(2.1)$ \\
\hline \multirow[t]{2}{*}{ TRP/ $\Sigma$ LNAA (\%) } & $\mathrm{T}+$ & $9.1(0.2)$ & $7.6(0.5)$ & $8.6(0.3)$ \\
\hline & $\mathrm{T}-$ & $8.8(0.2)$ & $2.0(0.4)$ & $7.6(0.2)$ \\
\hline \multirow[t]{2}{*}{ TYR (mmol/L) } & $\mathrm{T}+$ & $59.5(2.6)$ & $146.7(13.0)$ & $62.5(3.7)$ \\
\hline & $\mathrm{T}-$ & $59.8(3.2)$ & $142.4(12.0)$ & $57.9(2.8)$ \\
\hline \multirow[t]{2}{*}{ TYR/ $/ \sum$ LNAA $(\%)$} & $\mathrm{T}+$ & $11.4(0.4)$ & $18.0(1.0)$ & $11.7(0.7)$ \\
\hline & $\mathrm{T}-$ & $11.0(0.3)$ & $15.7(0.8)$ & $10.7(0.4)$ \\
\hline
\end{tabular}

tive side effects, as expressed by the summed side effect scores, as a result of TRP depletion versus placebo at $\mathrm{t}_{6}$ $(Z=-2.50 . \mathrm{df}=26, p=.013)$, although no one side effect was experienced significantly more often when analyzed separately.

Correlational analysis of POMS scores with side effects showed that the summed POMS and the summed vegetative side-effect scores were positively associated $(r=$ $.43, n=27, p=.024)$. However, there was no significant association between POMS subscales and vegetative side effect items on an item by item basis.

\section{Blood Levels}

Plasma TRP concentrations at baseline and at $t_{24}$ did not differ between groups and treatment conditions. The results are summarized in Table 3. Plasma TRP concentrations were $33 \%$ at $\mathrm{t}_{6}$ relative to the baseline value in the TRP-depletion condition (plasma tryptophan after TRP depletion versus placebo at $\mathrm{t}_{6}: F_{1,22}=85.03 ; p<$ $.0001)$. TRP to $\Sigma$ LNAA ratio at baseline did not differ between groups and treatment conditions. This ratio was $22 \%$ of the baseline at $\mathrm{t}_{6}\left(F_{1,22}=87.10 ; p<.0001\right)$ and $85 \%$ at $\mathrm{t}_{24}$ in the TRP-depletion condition $\left(F_{1,21}=\right.$ $7.79 ; p<.05)$. There were no differences between $\mathrm{FH}+/ \mathrm{FH}-$ groups as to TRP and TRP/ $\Sigma$ LNAA and no interaction between treatment and $\mathrm{FH}$. The tyrosine $(T Y R) / \Sigma$ LNAA ratio at $t_{6}$ was increased relative to $t_{0}$ and $\mathrm{t}_{24}$, both in the placebo and TRP-depletion sessions, but there was no difference between conditions.

After 24 hours, the plasma levels of TRP and the $\mathrm{TRP} / 2 \mathrm{LNAA}$ had returned practically to normal.

\section{Menstrual Cycle Phase}

In both the placebo and the TRP condition, 8 subjects participated in the test in the follicular phase (day 1 to 14) and four in the premenstrual phase (day 21 to 28). Two subjects in both conditions attended the test in the third week of the cycle.

\section{Study on the Pharmacokinetics of 24-Hour TRP Depletion}

\section{Methods and Materials}

\section{Subjects}

Seven healthy subjects ( 5 men, 2 women, aged 20 to 56 years; mean 32.9 years) were recruited to study TRP blood levels at 2-hour intervals during the 24 hours after TRP depletion. Apart from good physical health as the major inclusion criterion, exclusion criteria were excessive drinking and no history of depression. The study was approved by the Medical Ethics Review Committee of the University Hospital Maastricht, The Netherlands. All subjects signed voluntary informed consent forms before the study and were paid for their participation.

\section{Procedure}

Seven subjects arrived at the laboratory at 8:30 AM after an overnight fast. At $\mathrm{t}_{0}(9: 00 \mathrm{AM})$, baseline blood samples were collected and TRP-depletion treatment was started. Subjects ingested $100 \mathrm{~g}$ TRP-free amino acid mixture as quickly as possible, but within 2 hours and adhered to the TRP-depleted diet (see previous discussion) for 24 hours. Blood samples were taken using an intravenous catheter every 2 hours from $t_{0}$ to $t_{24}$. The subjects remained in the laboratory for 24 hours and were allowed to read, study, or watch television. A detailed description of all food and beverages consumed (time and amount) was kept by each subject. After the last blood samples at $t_{24}$, the subjects received a proteinrich meal to compensate for possible deficiencies. 


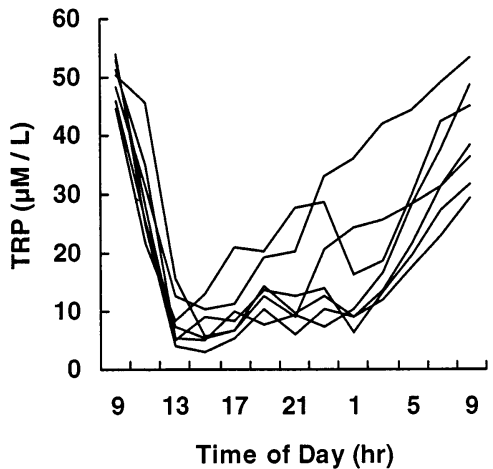

\section{Results}

Tryptophan levels in all 7 subjects declined rapidly after the TRP depleted amino acid mixture was ingested: TRP concentrations reached a minimum at $t_{4}$ in three subjects and at $t_{6}$ in four subjects. At its nadir, the mean TRP concentration was $12 \%$ of the baseline concentration. At $\mathrm{t}_{16}$, the average TRP level was still $32 \%$ of baseline value, and at $\mathrm{t}_{24}$ it was $81 \%$ of baseline. The average TRP/ $\sum$ LNAA ratio was lowest at $t_{4}$, when it was $5 \%$ of the baseline ratio. At $\mathrm{t}_{16}$, the average TRP/ $/ \mathrm{LNAA}$ ratio was still $28 \%$ of the baseline ratio, and at $\mathrm{t}_{24}$ it was $75 \%$ relative to baseline. The additional ingestion of $10 \mathrm{~g}$ of the TRP-depleted amino acid mixture at $\mathrm{t}_{7}, \mathrm{t}_{11}$, and $\mathrm{t}_{14}$ most probably had an effect on the TRP/ $\Sigma$ LNAA ratio (see Figure 1). Especially after $t_{14}$, a decrease in the ratio is seen, which cannot be accounted to anything else but the additional $10 \mathrm{~g}$ of the amino acid mixture. Two subjects accidentally did not receive the additional $10 \mathrm{~g}$ of TRPdepleted amino acid mixture at $\mathrm{t}_{14}$, which can clearly be seen in Figure 1 as their ratio did not decrease but increased instead.

\section{Discussion}

The aim of this study was to achieve a 24-hour lasting TRP depletion. The pharmacokinetic study showed that plasma TRP and the ratio TRP/ $\Sigma$ LNAA was significantly lowered at $\mathrm{t}_{6}$ and remained low until about $\mathrm{t}_{16}$. However, they normalized during the night when the subjects were sleeping. Possibly, the TRP pool was replenished by protein degradation during sleep.

Our hypothesis that mood would be more affected after 24 hours than after 6 hours of depletion was disproven. After an initial mood lowering $\left(\mathrm{t}_{6}\right)$, at $\mathrm{t}_{24}$ mood had returned to its baseline level. The data suggest that the relationship between low TRP and lowered mood is momentary. In a study investigating the effects of TRP depletion on 5-hydroxyindoleacetic acid (5-HIAA) concentration in the cerebrospinal fluid (CSF) (in humans), it was shown that CSF 5-HIAA concentrations were lowest 8 to 12 hours after the amino acid drink (Carpenter 1998). It would be interesting to assess mood not only at $\mathrm{t}_{6}$ but also at a time between $t_{8}$ and $t_{12}$, to confirm a presumed momentary relationship between brain 5HT turnover and mood.

Although a time lag exists between lowering of blood TRP and lowering of brain 5HIAA concentrations (in vitro studies suggest that brain 5HT neurons will turnover all available 5HT stores in about 1 to 2 hours after depletion of TRP; Lin et al 1969), we do not expect the same time lag to exist when blood TRP rises again after a period of depletion. If TRP would be orally administered during a TRP-depleted state, one would expect a rapid transport through the blood-brain barrier and a subsequent rapid rise of 5HT levels, since the tryptophan hydroxylase enzyme is normally unsaturated (Fernstrom 1977). The best estimate of brain 5HT is the ratio TRP/ 2 LNAA. As can be seen in the figure, the time-curve of TRP/ $\Sigma$ LNAA is almost equal to that of plasma TRP. Thus, we have reasons to believe that in our study, brain serotonin levels could easily have normalized by $t_{24}$.

Delgado and colleagues (1990) found a significant lowering of mood after 24 hours in remitted depressed patients, even though the TRP depletion was achieved only with an amino acid mixture and without additional diet. There are several reasons for a difference in outcome between our study and that of Delgado and co-workers (1990). First, Delgado and colleagues do not present TRP blood levels at $t_{24}$. Thus, it might be possible that TRP blood levels in their study have not returned to normal at $t_{24}$. Second, it could be that subjects who have been depressed show a different response to TRP depletion than normal subjects, due to either differences in TRP and/or 5HT metabolism, or a different emotional response to similar metabolic changes.

Our study differs from others by the addition of carbohydrates and fat to the AA mixture. It is generally very difficult to withhold carbohydrates for a period of 24 hours. Adding 
carbohydrates to the AA mixture is a way to provide the subjects' necessary nutrition in a standard manner. Furthermore, the carbohydrates were necessary to dissolve the amino acids. Carbohydrates, however, are known to increase insulin release, thus taking away several LNAAs from the circulation, which might enhance the uptake of TRP in the brain (Fernstrom 1981). However, this logic only applies to protein-free carbohydrate meals. In protein-containing meals, carbohydrates would fail to enhance brain TRP concentrations. Their ingestion causes both serum TRP concentrations and the concentrations of its transport competitors to rise by proportionally similar amounts, resulting in no net change in competition for uptake (Fernstrom and Fernstrom 1995). As the TRP/ $\Sigma$ LNAA ratio was convincingly low in our study, at least at $\mathrm{t}_{6}$, the addition of carbohydrates and fat to the AA mixture does not seem to have altered the desired effect of TRP depletion and hence, did not influence the results in a negative fashion.

\section{Family History, Gender, and Mood Response to TRP Depletion}

After TRP depletion, eight of 16 subjects (5 women and 3 men) with first-degree relatives with depression showed a depression of mood (with at least one point on the POMS depression scale) compared with only 1 (man) of 11 subjects without a family history of depression. This strongly suggests that family history plays an important role in the sensitivity to TRP depletion, as we expected. As can be seen from Table 2, the magnitude of the mood effects was only small [1.9 \pm 3.2 (SD) for the $\mathrm{FH}+$ group on a scale 0 to 24] as can be expected in normal subjects who have never been depressed. Benkelfat and co-workers (1994) found a similar effect, and of comparable magnitude, in male subjects with a highly positive family history for depression.

In our study, the group sizes would become very small if one was to statistically evaluate the main effects of gender and $\mathrm{FH}$ and their interactions. However within the $\mathrm{FH}+$ group, the 5 female subjects showed the strongest increases on the POMS depression score (range 4 to 10), whereas the 3 male subjects showed only an increase of one point. Nevertheless, the observed pattern of results appears to be quite compatible with the finding of other authors who report women to be more sensitive to the effects of TRP depletion than men (Ellenbogen et al 1996; Menkes et al 1994; Smith et al 1997a; Weltzin et al 1994).

\section{Menstrual Cycle Phase}

Ideally, testing should have been carried out in the follicular phase of the menstrual cycle. We did not attend to this rule. However, testing in both the placebo and the TRP-depletion condition took place in exactly the same phase of the menstrual cycle (except for one subject with missing data). Furthermore, eight out of 15 subjects took oral contraceptives and the question can be raised whether phase of the menstrual cycle is of great importance in these cases. Another way in which we tried to rule out confounding influences of menstrual phase is by excluding subjects who regularly experience significant mood swings in the course of the menstrual cycle.

\section{Side Effects}

Although increased POMS depression scores can not be explained by an increased incidence of nausea and other vegetative side effects in a causal manner, it would seem logical that they are associated in some way. There are abundant peripheral 5-HT receptors in the gastrointestinal tract. Subjective mood changes and an increase in gastrointestinal side effects after TRP depletion might both be associated to sensitized 5-HT receptors. The former might reflect increased central 5-HT receptor sensitivity, whereas the latter might reflect peripheral 5-HT receptor hypersensitivity. The data suggest that central or peripheral 5-HT receptors, or both, may be more sensitive in $\mathrm{FH}+$ subjects. However, six of the seven subjects who withdrew, mainly because of adverse events, were from the $\mathrm{FH}-$ group. We have no evidence that the $\mathrm{FH}+$ group tolerated the procedure better. Probably, the subjects in the $\mathrm{FH}+$ group were more motivated to continue their participation in the experiment after experiencing side effects because they were a relative of a depressed patient in our outpatient clinic.

\section{No Interference of TRP Depletion with Tyrosine Availability}

In discussing the limitations of the TRP-depletion method, it has been suggested that TRP depletion might interfere with TYR availability and that the change in ratio of TYR/ $\Sigma$ LNAA has not been measured in TRP-depletion studies (Reilly et al 1997). TYR availability could be of importance since TYR is the amino acid precursor for both noradrenaline and dopamine, both of which have been implicated in mood disorders. Assays of the plasma amino acids showed that tyrosine levels were increased substantially and the TYR/ $\Sigma$ LNAA ratio slightly at $t_{6}$, but not differently across treatment conditions (see Table 3). Thus, theoretically, brain levels of catecholamines could have increased at $\mathrm{t}_{6}$, but again, in a similar fashion in the TRP-depletion and placebo conditions.

\section{Conclusion}

The previously described mood-lowering response to TRP depletion 6 hours after the start of treatment was con- 
firmed and was shown to be more prominent in subjects with a first-degree relative with depression. A heightened sensitivity to changes in 5-HT concentrations in $\mathrm{FH}+$ subjects is a possible explanation for this finding. The hypothesized increased effect of prolonged tryptophan depletion on mood at 24 hours after treatment administration could not be demonstrated because we did not succeed in maintaining low tryptophan levels throughout the night, despite maintenance treatment doses and a tryptophan-deficient diet.

This study was made possible by a grant from the Maastricht University's Hospital Clinical Research Fund ("Profileringsfonds"). Furthermore, we thank H. van Eijk and D. Rooyakkers for the analysis of plasma amino acids.

\section{References}

Arrindell WA, Ettema JHM (1986): SCL-90. Een multidimensionele psychopathologie indicator [SCL-90. A multidimensional indicator of psychopathology]. Lisse, The Netherlands: Swets \& Zeitlinger.

Benkelfat C, Ellenbogen MA, Dean P, Palmour RM, Young SN (1994): Mood-lowering effect of tryptophan depletion. Enhanced susceptibility in young men at genetic risk for major affective disorders. Arch Gen Psychiatry 51:687-697.

Biggio G, Fadda F, Fanni P, Tagliamonte A, Gessa GL (1974): Rapid depletion of serum tryptophan, brain tryptophan, serotonin and 5-hydroxyindoleacetic acid by a tryptophan-free diet. Life Sci 14:1321-1329.

Carpenter LL (1998): Tryptophan depletion during continuous CSF sampling in healthy human subjects. Neuropsychopharmacology 19:26-35.

Charney EA, Weissman MM (1988): Epidemiology of depressive and manic syndromes. In: Georgotas A, Cancro R, editors. Depression and Mania. New York: Elsevier, pp 26-52.

Cleare AJ, Bond AJ (1995): The effect of tryptophan depletion and enhancement on subjective and behavioral aggression in normal male subjects. Psychopharmacology 118:72-81.

Delgado PL, Charney DS, Price LH, Aghajanian GK, Landis H, Heninger GR (1990): Serotonin function and the mechanism of antidepressant action: Reversal of antidepressant-induced remission of rapid depletion of plasma tryptophan. Arch Gen Psychiatry 47:411-418.

Delgado PL, Charney DS, Price LH, Landis H, Heninger GR (1989): Neuroendocrine and behavioral effects of dietary tryptophan restriction in healthy subjects. Life Sci 45:23232332.

Delgado PL, Price LH, Miller HL, et al (1991): Rapid serotonin depletion as a provocative challenge test for patients with major depression: Relevance to antidepressant action and the neurobiology of depression. Psychopharmacol Bull 27:321330.

Ellenbogen MA, Young SN, Dean P, Palmour RN, Benkelfat C (1996): Mood response to $\sim$ acute tryptophan depletion in healthy volunteers: Sex differences and temporal stability. Neuropsychopharmacology 15:465-474.

Endicott J, Andreasen NC, Spitzer RL (1975): Family HistoryResearch Diagnostic Criteria. New York: Biometrics Research, New York State Psychiatric Institute.

Fernstrom JD (1977): Effects of the diet on brain neurotransmitters. Metabolism 26:207-223.

Fernstrom JD (1981): Dietary precursors and brain neurotransmitter formation. Ann Rev Med 32:413-425.

Fernstrom MH, Fernstrom JD (1995): Brain tryptophan concentrations and serotonin synthesis remain responsive to food consumption after the ingestion of sequential meals. Am J Clin Nutr 61:312-319.

Kent JM, Coplan JD, Martinez J, Karmally W, Papp LA, Gorman JM (1996): Ventilatory effects of tryptophan depletion in panic disorder: A preliminary report. Psychiatry Res 64:83-90.

Lam RW, Zis AP, Grewal A, Delgado PL, Charney DS, Krystal JH (1996): Effects of rapid tryptophan depletion in patients with seasonal affective disorder in remission after light therapy. Arch Gen Psychiatry 53:41-44.

Lin RC, Costa E, Neff NH, Wang CT, Ngai SH (1969): In vivo measurement of 5-hydroxytryptamine turnover rate in the rat brain from the conversion of $\mathrm{C}^{14}$-tryptophan to $\mathrm{C}^{14}-5$-hydroxytryptamine. J Pharmacol Exp Ther 170:232-238.

McNair DM, Lorr M, Droppleman LF (1971): Manual for the Profile of Mood States. San Diego: Educational and Industrial Testing Service.

Menkes DB, Coates DC, Fawcett JP (1994): Acute tryptophan depletion aggravates premenstrual syndrome. J Affect Disord 32:37-44

Moeller F, Dougherty D, Swann A, Collins D, Davis C, Cherek D (1996): Tryptophan depletion and aggressive responding in healthy males. Psychopharmacology 126:97-103.

Moja EA, Antinoro E, Cesa-Bianchi M, Gessa GL (1984): Increase in Stage 4 after ingestion of a tryptophan-free diet in humans. Pharmacol Res Comm 16:909-914.

Nishizawa S, Benkelfat C, Young SN, et al (1997): Differences between males and females in rates of serotonin synthesis in human brain. Proc Natl Acad Sci U S A 94:5308-5313.

Park SB, Coull JT, McShane RH, et al (1994): Tryptophan depletion in normal volunteers produces selective impairments in learning and memory. Neuropharmacology 33:575588.

Reilly JG, McTavish SFB, Young AH (1997): Rapid depletion of plasma tryptophan: A review of studies and experimental methodology. J Psychopharmacol 11:381-392.

Riedel WJ, Klaassen T, Deutz NEP, Van Someren A, Van Praag HM (1999): Tryptophan depletion in normal volunteers produces selective impairment in memory consolidation. Psychopharmacology 141:362-369.

Schaechter JD, Wurtman RJ (1989): Tryptophan availability modulates serotonin release from rat hypothalamic slices. J Neurochem 53:1925-1933.

Sheehan D, Lecrubier Y, Janavs J, et al (1994): MINI International Neuropsychiatric Interview. Tampa: University of South Florida.

Smith KA, Clifford EM, Hockney RA, Clark DM (1997a): Effect of tryptophan depletion on mood in male and female volun- 
teers: A pilot study. Human Psychopharmacol Clin Exp 12:111-117.

Smith KA, Fairburn CG, Cowen PJ (1997b): Relapse of depression after rapid depletion of tryptophan. Lancet 349:915-919.

Smith SE, Pihl RO, Young SN, Ervin FR (1987): A test of possible cognitive and environmental influences on the mood lowering effect of tryptophan depletion in normal males. Psychopharmacology 91:451-457.

Spitzer RL, Endicott J, Robins E (1975): Research Diagnostic Criteria (RDC) for a Selected Group of Functional Disorders, Ed. 2. Biometrics Research. New York: New York State Psychiatric Institute.

Van Eijk HM, Huinck MP, Rooyakkers DR, Deutz NE (1994): Automated simultaneous isolation and quantitation of labeled amino acid fractions from plasma and tissue by ion-exchange chromatography. J Chromatogr B Biomed Appl 660:251-257.

Van Eijk HM, Rooyakkers DR, Deutz NE (1993): Rapid routine determination of amino acids in plasma by high-performance liquid chromatography with a 2-3 microns Spherisorb ODS II column. J Chromatogr 620:143-148.
Weltzin TE, Fernstrom MH, Fernstrom JD, Neuberger SK, Kaye WH (1995): Acute tryptophan depletion and increased food intake and irritability in bulimia nervosa. Am J Psychiatry 152:1668-1671.

Weltzin TE, Fernstrom JD, McConaha C, Kaye WH (1994): Acute tryptophan depletion in bulimia: effects on large neutral amino acids. Biol Psychiatry 35:388-397.

Young SN, Ervin FR, Pihl RO, Finn P (1989): Biochemical aspects of tryptophan depletion in primates. Psychopharmacology 98:508-511.

Young SN, Pihl RO, Ervin FR (1988): The effect of altered tryptophan levels on mood and behavior in normal human males. Clin Neuropharmacol 11(Suppl 1):S207-215.

Young SN, Smith SE, Pihl RO, Ervin FR (1985): Tryptophan depletion causes a rapid lowering of mood in normal males. Psychopharmacology 87:173-177.

Zimmermann RC, McDougle CJ, Schumacher M, et al (1993): Effects of acute tryptophan depletion on nocturnal melatonin secretion in humans. J Clin Endocrinol Metab 76:1160-1164. 